\title{
Banquetes y rituales colectivos en el suroeste peninsular
}

\author{
Luis Berrocal-Rangel \\ Departamento de Prehistoria y Arqueología \\ Universidad Autónoma de Madrid. \\ TIf. 91.497.4609/4600.
}

\section{Resumen}

El trabajo propone una interpretación diacrónica de las costumbres religiosas en el suroeste prerromano relacionadas con la iglesia masiva de bebidas y comidas dentro de contextos rituales sagrados. Así se destaca la importancia de estos banquetes colectivos, sin presencia explicíta de las imágenes divinas durante la Edad de Hierro, y con la asistencia de numerosas figuritas sagradas durante los primeros siglos de la civilización romana en el Suroeste peninsular. Junto a esta diferencia, los banquetes demuestran el abandono de una paridad entre la ingesta de comida y bebida, con el sacrificio explícito de grandes animales como acto central del rito, como ocurría en época preromana, para favorecer la bebida masiva de un ñíquido costoso, posiblemente vino, acompañado de la toma colectiva de frutos y manjares secos, acompañados de salsas, durante la denominación romana.

Palabras Clave: Banquetes, santuarios, Célticos, rituales, sacrificios, favissae.

\section{Summary}

In this paper we put forward a new diachronic interpretation of religious rituals among the Celtic peoples in the Southwestern areas of the Iberian Peninsula during the Iron Age and the early centuries of Roman rule. We emphasize the outstanding importance of collective feasts close to and in shrines during the Second Iron Age. These banquets werw jheld around animal sacrifices and the subsequent ingestion of meat and a kind of local beer. Apparently, there was not a explicit presence of sacred images in these feasts in pre-Roman times. However, during the Roman perod, different favissae found in archaeological sites belonging to the Beaturia Celticorum have yielded numerous terracotta figurines of Roman goddesses besides a large number of small wine cups and big plates, probably for dried fruits and food accompanied by sauces. We consider these changes as true indicators of deep transformations in social and ideological structures among the Celtici in Roman times.

Keywords: feasts, food and drinks, shrines, Celts, rutual, sacrifices, favissae

\section{INTRODUCCIÓN}

La mera idea de redactar las siguientes páginas supone, para este Autor, el hecho público de asumir la inevitable partida de quien fue luz y guía de todos sus trabajos, especialmente los relacionados con el tema elegido.

María del Rosario Lucas, nuestra "Charo", fue siempre la mejor maestra que un doctorando e investigador poco iniciado pudiera imaginar, pues su formación humanística y su memoria enciclopédica le permitía asesorar sobre cualquiera de los temas que se le requiriese, y la generosidad de su carácter era garantía de provecho para el alumno que, como quien escribe estas paginas, pasara tantos años disfrutando de su magisterio. No es de extrañar, por tanto que, en nuestra bibliografía, no figuren los temas del Arte rupestre o del Paleolítico en general, ni sea- 
mos especialistas en la Religiosidad de los Pueblos ibéricos, ámbitos reconocidos en las investigaciones de Charo Lucas y, sin embargo, podemos afirmar que algunos de los trabajos que realizamos, y a los que siempre entregó sus generosas introducciones, trataron de temas que para ella eran de especial atractivo y enriquecimiento, especialmente los relacionados con la "comida y la bebida", y las formas de prepararlas y de ingerirlas. Quizá porque el jamón sea un producto especialmente emblemático de su tierra turolense y de la nuestra extremeña, lo cierto es que siempre compartimos el interés por la cocina y los alimentos, y siempre recordaremos su regocijo ante dos modestas contribuciones nuestras sobre el consumo del cerdo en la Antigüedad, en nada homologables a los señeros trabajos que, ella misma, le dedicó al tema (Berrocal-Rangel et alii 1992 y 1994; Lucas Pellicer 1991...').

Que la alimentación es uno de los motores de la propia vida es un perogrullo que, por ello, no necesita explicación alguna, pero determinar las maneras y las vías por las que los pueblos han manifestado sus propias peculiaridades respecto a un tema tan universal, es un ejercicio de suma complejidad que ha marcado una importantísima línea de especialización (Cohen 1984; VV.AA. 1987; Murray y Schoeninger 1988; Alimenta 1991; Montanari 1993; Celestino 1995 y 1999.....). Tal complejidad viene condicionada por la naturaleza ambivalente de la "cocina", capaz de asumir con rapidez aportaciones novedosas procedentes de diversas tradiciones a la vez que mantener, a veces de forma increíble, sus propios gustos y costumbres.

Desde este enfoque, nuestro interés por el análisis del testimonio arqueológico procedente de la Prehistoria reciente pretende valorar la diversidad frente a la convergencia y a la comunidad del consumo y presentación de ciertos productos, a menudo cargados de un reconocido significado social. Así, ante las implicaciones diferenciales tradicionales aplicadas al hervido o al asado como tratamiento, o a la presencia de ágapes masivos o selectivos, destaca la aparente similitud de uso de bebidas como el vino y la cerveza, o de alimentos como la mantequilla, la manteca o la bellota.

La Arqueología protohistórica del Suroeste peninsular no es especialmente rica en datos

1 Todos aquellos que tuvimos el honor de ser sus compañeros conocemos que Charo estaba trabajando desde hacía varios años en un libro sobre la cocina en la Antigüedad. Desgraciadamente este trabajo, que posiblemente ya había concluido una aparentemente intermina- relacionados con la comida y la bebida, tanto por la escasez de testimonios como por la falta de los análisis específicos. Si bien se han propuesto interpretaciones especialmente sugerentes para algunos hallazgos afortunados, la realidad es que no son más que meras "anécdotas" en nuestro conocimiento sobre las costumbres culinarias de estas poblaciones protohistóricas y la trascendencia social que de ellas se deriva.

Tal panorama es consecuencia de la escasez de yacimientos excavados, aunque han sido comparativamente pródigos en hallazgos que desde nuestra óptica podemos calificar de "significativos" sin asumir un grado de error exagerado. Así consideramos aquellos acontecidos en contextos singulares cargados de una naturaleza incuestionablemente ritual, cuando no sagrada. El caso del Depósito de Garvâo (Aljustrel, Baixo Alentejo) nos abrió esta línea de estudio, después incrementada notablemente por hallazgos tan afortunados como el mismo Santuario central del Castrejón de Capote (Higuera la Real, Badajoz). Otros ejemplos son menos conocidos, como el Depósito de Vaiamonte (Castelo Branco, Alto Alentejo) y los santuarios de San Pedro y Cuevas de Fuentes de León (Badajoz). Incluso, más allá de estos contextos, ahora es factible la interpretación de hallazgos aislados y difícilmente reconocidos, como los cuencos y vasos de plata del tesoro de Monsanto (Castelo Branco, Beira Baixa) que aportan a los anteriores, una óptica diferente del tema tratado.

\section{DoCumentación}

2.1. El Castrejón de Capote era un asentamiento totalmente desconocido con anterioridad a su descubrimiento arqueológico (BerrocalRangel 1989). Tras los primeros sondeos, el yacimiento fue rápidamente caracterizado en plena Época romano-republicana, aunque su principal aportación vino de la mano de la identificación de un espacio extraordinario datado en un período anterior (Ss. IV - II a.C.) y emplazado en el mismo centro geográfico del poblado (BerrocalRangel 1994).

Es importante destacar que el Castrejón, pese a situarse en el entorno de la citania célticoromana de Nertóbriga (El Coto, Fregenal de la Sierra) y presentar una organización intramuros

ble fase de recogida de datos, se encontraba aún demasiado poco elaborado fuera de su "cabeza", como para que se le pueda dar una forma concreta aunque le dedicó un curso de doctorado en el año 2002-2003 


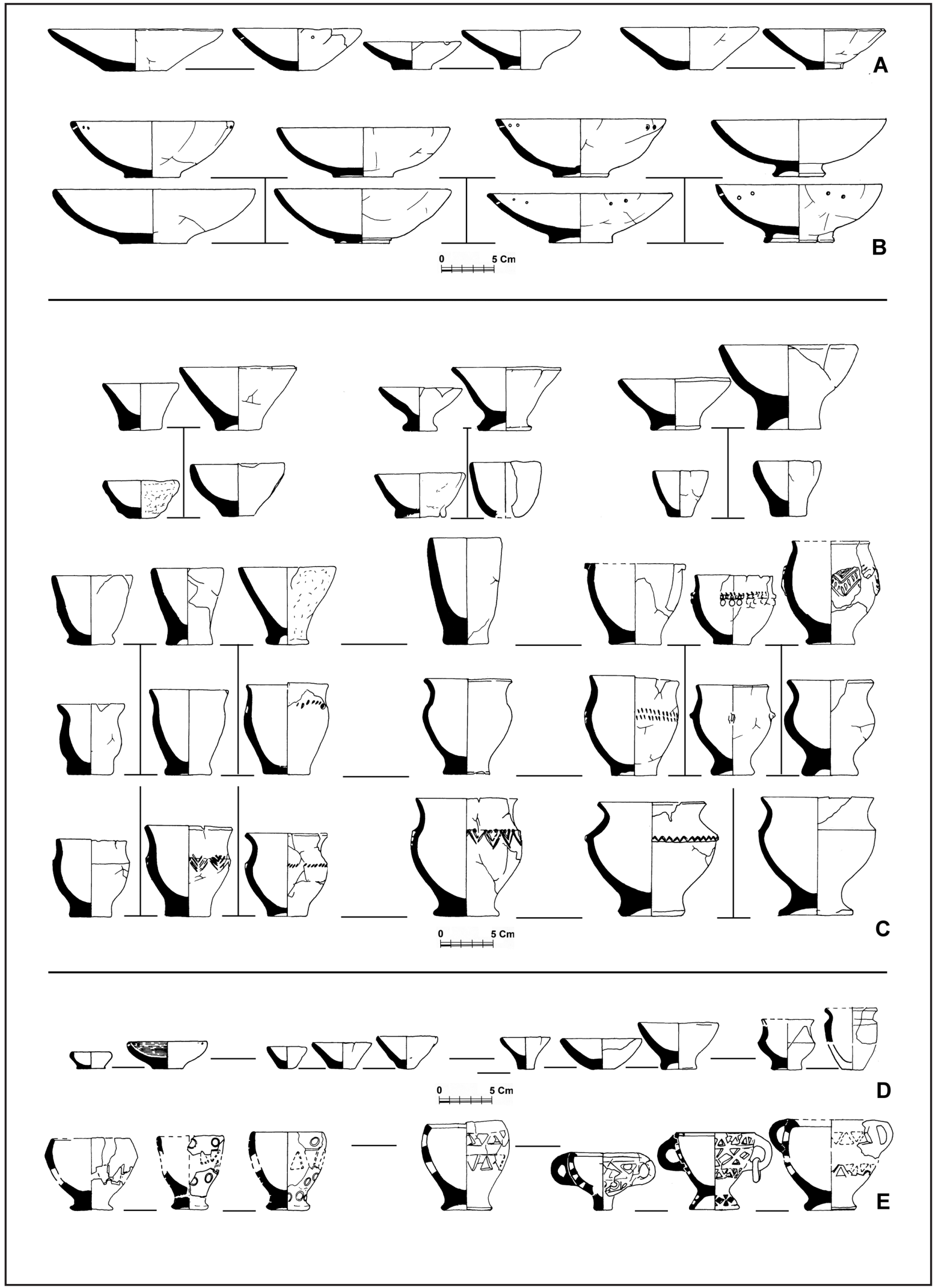

Figura 1: Selección representativa de las vasijas del Santuario de Capote: A. Escudillas modeladas; $B$. Escudillas a torno; C. Copas y vasos modelados; D. Vasitos miniatura; E: Vasos rituales (foculi), sahumerios o quemadores (a partir de Berrocal-Rangel 1994). 
compleja, responde a un típico castro de ribero del Occidente peninsular, con una extensión poco mayor a 3 ha. y un emplazamiento dominado desde todos sus alrededores, excepto por el Occidente, sonde se localiza el horcajo de los ríos que lo circunvalan. Quizá por todo ello sorprende el emplazamiento central del Santuario, indicando una importancia que, en principio, no parece acorde con el tipo de poblado ni de emplazamiento: no es un oppidum, ni ocupa un lugar destacado en el paisaje. Sin duda por lo mismo, la explicación más adecuada se planteó en torno a su valor comunitario de los ritos celebrados en este lugar respecto al propio castro (Almagro-Gorbea y Berrocal 1997: 579-581).

Pero tal adscripción, que es coherente con los vestigios hallados, implicaría la concesión de una importancia extraordinaria hacia los ritos que se realizaban en tal espacio. Y la misma configuración de éste, una estancia de planta trapezoidal de $4 \mathrm{~m}^{2}$ cerrada por tres de sus lados y abierta por el tercero hacia una plaza, sobre cuyo suelo destaca por estar elevado en un podio, es extraordinaria no pudiéndose equiparar con nada de lo conocido en la Arquitectura doméstica del poblado. En consonancia, su interior se articula exclusivamente entorno a una gran mesa-altar de piedra, disponiéndose un banco corrido a lo largo de las tres paredes de la estancia. Literalmente no hay espacio más que para sentarse en torno a dicha mesa (Berrocal-Rangel 1994: 47 ss.).

Según su emplazamiento estratigráfico es fácil adjudicar al Santuario de Capote una vida de uso entre mediados del siglo IV a.C. y mediados del II a.C., momento en el cual fue rápidamente amortizado debido a una acción contundente sobre los restos de un ritual acabado de terminar. Por ello, estos vestigios y el santuario al completo fue amortizado y condenado mediante su soterramiento intencionado, y posiblemente la prohibición de construir sobre él, pues no se encontró nada en el nivel de ocupación posterior (Berrocal-Rangel 1994: 52-53).

De los varios miles de fragmentos cerámicos y óseos contenidos en él, y de los instrumentos metálicos (parrilla, espetones, badila, cuchillos), es fácil colegir la realización de un gran festín, en el cual se sacrificaron y desmembraron mediante tanotocenosis entre 23 y 24 cuadrúpedos, posiblemente formando parejas o tríos (según se desprende de la presencia selectiva de restos faunís-

2 En estos conjuntos el término de "vaso" se refiere a un recipiente de tamaño mediano, capaz de ser asido con una mano, y con perfil en "S", ticos: Morales y Liesau 1994). De las cerámicas, una vez reducidas a las piezas completas o semicompletas pudo colegirse la presencia de un millar de vasijas de las cuales se registraron 300 juegos de vaso- ${ }^{2}$, escudilla y vasija, así como una treintena de "quemadores" o foculi. Todo este conjunto, y otras piezas significativas halladas en sus alrededores que se fechan entre los siglos VI a.C. y I a.C. (falcata, losa inscrita del SW, collares articulados.......), permite valorar una ausencia significativa, la de figuras de aspecto o carácter sacro, así como también la falta de ex-votos "tradicionales" (a menos que se consideren como tales el centenar y medio de fusayolas documentadas, un tercio de ellas ricamente decoradas). Por todo y la definición de este recinto como un santuario de carácter comunitario no exento de un cierto trasfondo ideológico gentilicio parece bien fundamentada, especialmente si comprobamos el carácter peculiarmente indígena de las vasos y vasijas de almacén halladas, así como la interpretación de estos foculi, sahumerios o incensarios fácilmente deducibles de las formas tan concretas que presentan. En un trabajo anterior, junto con el Prof. Almagro-Gorbea, planteamos la sugerente posibilidad de considerarles como portadores del fuego doméstico con el que se conforma el fuego comunitario tal como se realizaba entre los rituales latinos a Vesta (Dumezil 1977: 277). De formas muy similares, los foculi latinos servían para recibir incienso y realizar libaciones con vino frente al fuego vestal del altar dónde se quemaban las ofrendas sacras (“....nec licere vel provata vel publica sacra sine foco fieri...": Serv. Ad. Aen. 3, 134). Y ambos, fuego y recipiente, venían a representar el concepto gentilicio de la estructura social, propio de las comunidades indoeuropeas (Almagro-Gorbea 1996: 103).

Así el Santuario central de Capote nos proporciona el ejemplo de la realización de una fiesta de suma importancia para la comunidad que lo habita, fiesta encaminada a propiciar la participación colectiva mediante la ingesta de carne y de bebida. No conocemos qué tipo de líquido se consumía pero sí sabemos que lo era en paridad con la carne, pues el número de vasos es similar al de escudillas y, además, es formalmente significativa la diferencia entre ambos, a favor de la singularidad de las primeras, fabricadas a mano y ricamente decoradas. Pero si hallazgos posteriores permiten tener la certeza del consumo del

carenado o no, cuya base, marcada, no destaca tanto como para cosiderarse "copa". 


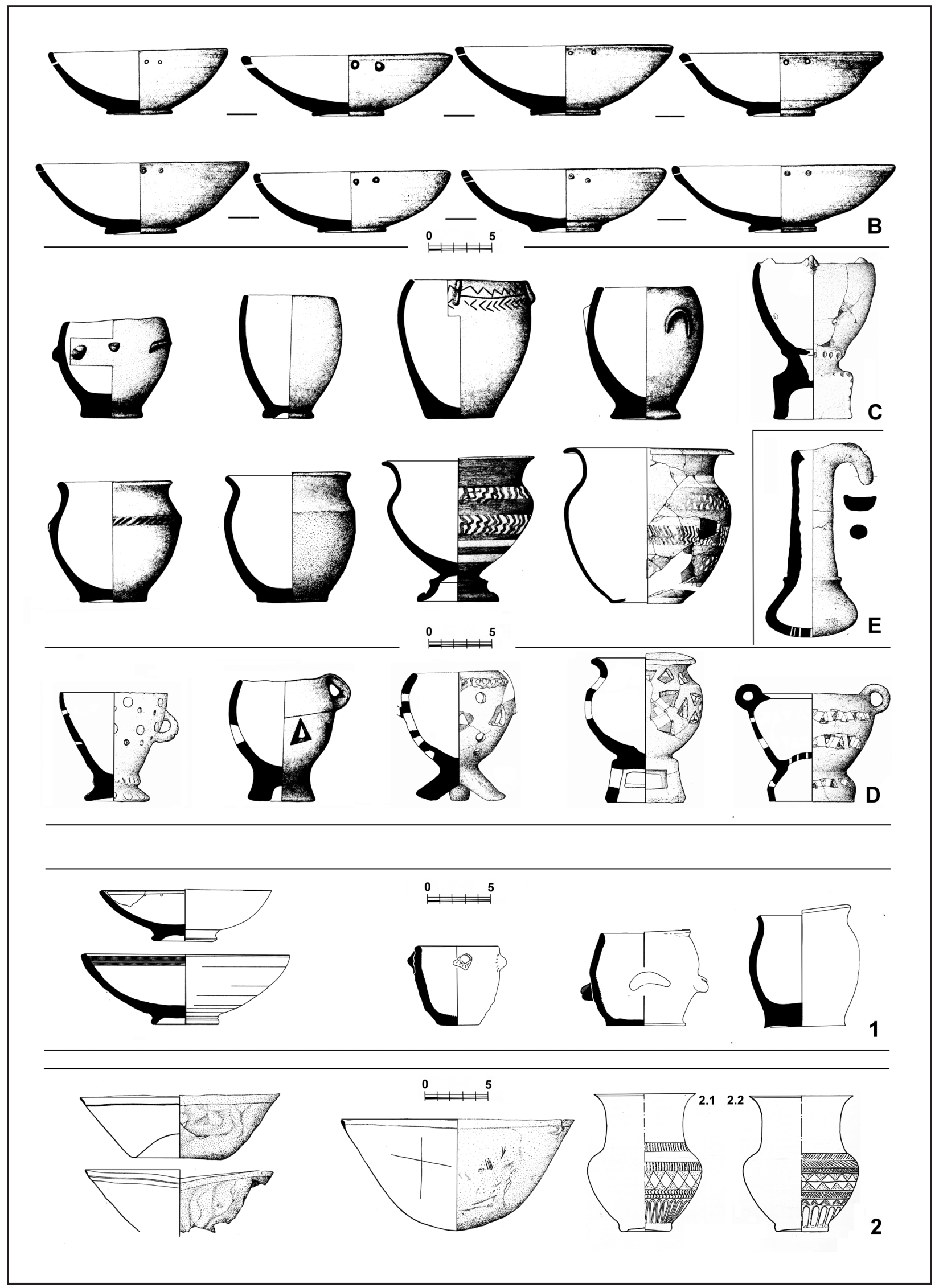

Figura 2: Selección de vasijas sagradas de la favissa de Garvâo: B. Escudillas a torno; C. Copas y vasos modelados; D. Vasos rituales (foculi), sahumerios o quemadores; E. Aspergyllus; 1. Vasijas de Vaiamonte; 2. Tesoro de Monsanto y vaso del MANMadrid (a partir de Beirâo et alii 1985; Fabiâ 1999; Gomes y Beirâo 1988). 
vino en una tierra poco apta para las vides como es la Beturia Céltica, nada pudimos obtener de los análisis efectuados en relación con el contenido de las vasos que bien pudo ser algún tipo de cerveza, vino o cualquier otra bebida obtenida por fermentación vegetal (Plinio, NH, XIV, 149).

Sobre el particular, en estudios anteriores hemos especulado sobre la celebración de este gran festín interrumpido trágicamente, considerándolo bien un acto cotidiano propio de un ciclo sagrado similar al Céltico, bien como un acto extraordinario, aunque no inusual, acontecido por motivos no menos singulares. Además es interesante comentar que diversos indicios como la orientación SWS del Santuario y noticias aportadas por los autores greco-romanos, nos llevaron a platear la posibilidad de que el ritual se hubiese interrumpido en algún momento avanzado del Otoño. Tal planteamiento, que no tiene más que indicios plausibles, se adecua bien a las dos interpretaciones anteriores pues, si se tratara de un acto ordinario del ritual comunitario respondería al gran festín del Samonios que, durante varios días, se celebraba entre los pueblos celtas para festejar el final del verano a comienzos del mes de Noviembre en el Calendario cristiano. Tanto el tipo de ritual como la descripción del emplazamiento responden muy bien a aquellos celebrados entre galos y celtas britanos (Markale 1989: 182184). Pero si se tratase de un acto extraordinario, las fuentes greco-romanas también aportan información sobre la celebración de festines similares consumidos antes de entrar en batalla, como aconteció entre los numantinos según refiere Orosio (Hist., V, 7, 13-14). Y, en tal caso, este autor griego comenta que lo ingerido en Numancia fue una especie de cerveza de trigo llamada celia: "Finalmente [los numantinos en el 133 a.C.] salieron de pronto todos por dos puertas tras haber ingerido gran cantidad no de vino, por cuanto aquel lugar no lo produce, sino de un jugo de trigo de confección artesana al que llaman celia, porque se produce por calentamiento...." (Quesada 1994: 108-113).

Sea como fuere no nos caben dudas sobre el valor sagrado y comunitario de este lugar, que demuestra cómo las poblaciones y del Suroeste celebraban ritos específicos en los que, acorde a la Ideología celta, no tenía porqué ser manifiesta la figura o la forma de la Divinidad, ni restringida la actuación de sus participantes.

2.2. El Castelo Velho de Vaiamonte pasa por ser uno de los principales oppida al Sur del Tajo, ya conocido desde inicios del siglo XX por el hallazgo a sus pies de un casco Montefortino y de una punta de lanza (Vasconcellos 1929....: una visión reciente de conjunto en Fabiâo 1996: 35 ss.). Por ello, y porque durante los años 40 del pasado siglo la excavación de la cercana villa de Torre de Palma atrajo la atención sobre la comarca, Manuel Heleno procedió a una serie de sus intervenciones "extensivas" como era su costumbre, de las que no trascendió más que algunas noticias aisladas, pese a la incuestionable personalidad de sus materiales (que posteriormente hicieron escribir a José Arnaud y Teresa Gamito un conocido artículo sobre la cerámica estampillada del Sur de Portugal: 1974-1977). Desde entones, fuera de la dedicación contemplada en obras generales (Berrocal-Rangel 1992: 312-315...), sólo el trabajo de conjunto realizado por Carlos Fabiâo nos ofrece un intento de reconstrucción e interpretación integral de los hallazgos acontecidos durante las excavaciones de Heleno, y masivamente almacenados en el Museu Nacional de Arqueología Leite do Vasconcellos de Lisboa (Fabiâo 1996).

A partir del material depositado en el MANLV, C. Fabiâo destaca la presencia de un buen número de vasos y escudillas enteros o semicompletos, junto a un importante conjunto de quemadores y a un millar y medio de fusayolas-, muchas de ellas con decoraciones de gran detalle. Este material le permite "colocar algumas interrogaçôes quanto à natureza das áreas escavadas, infelizmente impossíveis de esclarecer cabalmente. Penso que nâo seré descabido supor que no descurso da escavaçâo possa ter sido atingido um local de características análgas à do chamado altar do povoado do Castrejón de Capote (Higuera la Real, Badajoz), embora a equipa encarregue dos trabalhos de tal se nâo tenha apercebido. O conjunto dos materiais recolhidos junto aquela estrutura nâo diferem em variedade, qualidade e estado de conservaçâo de uma parte do espólio de Vaiamonte.....Tal hipótese ganha maior verosimilihança, atendendo às características de que se revisteram as investigaçôes em Vaiamonte e, bem entendido, ao facto de se nâo conhocer à época nenhuma outra estrutura desde tipo, aliás, de muito fraca visibilidade arqueológica, passível, portanto, de passar despercibida no decurso de uma intervençâo pouco cuidada e deficientemente orientada." (Fabiâo 1996: 51-52).

Efectivamente, el conjunto de materiales referidos responde inequívocamente al mismo horizonte y composición que el proporcionado por el Altar de Capote, aunque las circunstancias y el momento de las intervenciones a lo largo de las décadas de los años cuarenta y cincuenta del pasado siglo no aportan otro dato concluyente para este tipo de construcción que, aún siendo la única documentada como tal, debería haber sido frecuente en los ámbitos celtíberos e iberos (algunas se coligen de hallazgos afortunados como en El 
Amarejo, Alhónoz.....: Berrocal-Rangel 1994: 273274; Almagro-Gorbea y Berrocal 1997). Pero el paralelo más cercano geográfica y culturalmente es el excepcional depósito votivo de Garvâo, un conjunto de materiales idénticos a los hallados en Capote y Vaiamonte y cuya amortización se sitúa, con seguridad, a finales del siglo III a.C. gracias a la aparición de un hemidracma gaditano de esta fecha (Beirâo et alii 1985: 91, nº 81; Correia 1996: 102).

2.3. El Castelo de Garvâo es una fortificación medieval cristiana emplazada en los límites meridionales del Alentejo, y adscrita a la Orden de Santiago, dominante casi en exclusiva tras la desaparición de los templarios tanto en estos territorios como en los cercanos de Extremadura.

Independientemente de la existencia de un emplazamiento anterior, lo cierto es que Garvâo no trascenderá en la Historia hasta 1981 cuando, a raíz de la canalización de la Rua do Castelo, se documentó una acumulación excepcional de vasijas cerámicas que mostraban claras disposiciones de un ordenamiento intencionado. Realizada una excavación restringida al tramo afectado, se pudo documentar parte de una monumental favissa de 10 por $5 \mathrm{~m}$. de longitud de ejes, excavada en la misma roca madre de la ladera suroriental del castillo. El desnivel propio de este lugar fue neutralizado mediante la construcción de un pequeño muro de lajas de pizarra en el extremo SE de la fosa, de perfil aproximadamente oval (Beirâo et alii 1985: 58-61).

Las circunstancias del hallazgo y la inclinación del terreno impidieron documentar la manera en la que fue cubierta la fosa, aunque parece soterradada con un empedrado de losas de pizarra (Correia 1996: 102; 1999: 704). Sí se reconoce, tras el levantamiento de los materiales cuidadosamente colocados en su interior, la pavimentación del suelo con lajas de pizarra y la presencia de restos de un animal y de un cráneo humano, junto a un hacha de piedra pulimentada que había sido usada para seccionar el citado cráneo, éste identificado como perteneciente a una mujer adulta de mediana edad (Fernándes 1986: 78; Antunes y Cunha 1986: 84).

Sobre ellos, y hasta un metro de altura, se localizaron numerosos contenedores cerámicos que, a su vez, se presentaban repletos de vasijas menores. Un interés inicial por ocupar todo el espacio disponible de la fosa se demostró al comprobarse

3. Sin duda son tipos simples derivados de tradiciones anteriores, no tanto orientalizantes como "pre-coloniales", aunque bien desarrollada en ambientes mediterraneizados (Lorrio 1988-1989: 283 ss.). Aún así, no creemos que cómo se utilizaron, incluso, las esquinas y los intersticios entre los contenedores para situar otros recipientes, confirmando con ello la sincronía del acto de la deposición. Incluso, el afán por encajar todo el material previsto llevó a romper los cuellos de los contenedores más grandes para conseguir un diámetro de boca máxima y facilitar la colocación en su interior de múltiples escudillas (Beirâo et alii 1985: 60).

La variedad de vasijas depositadas es enorme, aunque prevalece un aspecto generalizado de fábricas indígenas, realizadas a mano y generósamente decoradas, de aspectos tan parecidos a las de Capote que bien pudieran confundirse entre ellas. Como en el castro extremeño, sólo las numerosas escudillas y algunas piezas mayores pintadas remiten a producciones "turdetanas" que contrastan fuertemente con el resto de los materiales. En efecto la presencia de estas escudillas lisas, bien cocidas y acabadas, con tamaños estandarizados y a menudo con dos agujeros propios para ser colgadas o sujetas al borde de una vasija mayor, corresponde a lo contemplado en Capote y en Vaiamonte, en números, pastas y dimensiones- $^{3}$. De igual forma, la similitud de ritos se refrenda en la apariencia de los numerosos vasos hechos a mano y de los "quemadores".

Sin embargo entre estos materiales hay también diferencias considerables, en parte derivados del mayor número de Garvâo pero también de un importante cambio en la naturaleza sacra del ritual y de la comunidad que lo respalda, aquí calificada de ámbito "para-urbano" (Correia 1996: 105-106). Por ejemplo, en el depósito bajo alentejano se localizó un significativo aspergyllus y otros materiales cuyas funciones religiosas fueron destacadas en un oportuno trabajo de Joaquín Barrio a partir de paralelos hallados en las excavaciones de un santuario doméstico en el oppidum vacceo de Cuéllar (Beirâo et alii, 1985: 108; Barrio 1987 y 1999: 189 y 228). Más significativos son los hallazgos de ex-votos en forma de una docena de placas de plata y oro con ojos repujados. Pese a la identificación púnica propuesta por sus excavadores a partir de una de éstas, excepcional en el conjunto por cuanto representa una cabeza y torso femenino con aparente tocado, difícilmente identificada como una Astarté-Tanit sincretizada en Ataecina (Gomes y Silva 1994: 38), la realidad es que este tipo de ofrenda en propia de santuarios galos y como los hallados en las Sources de la Seine

en fechas prerromanas estas escudillas sirviesen para la bebida como propone D. Ruiz Mata para aquellos remotos precedentes del Bronce Final (1995: 181 ss.). 
(Borgoña, F.), las Sources des Roches à Chamalières (Clermont-Ferrand, F.), Bourbonneles-Bains (Haute-Marne, F.) o en San Pietro Montagnon (I.), relaciones lejanas intensificadas por la aparición en Garvâo de dos pequeños modelos de mandíbulas inferiores humanas fabricados en cerámica y pasta vítrea respectivamente (Beirâo et alii 1985: 94, frag. 115; Correia 1996: 104). Son santuarios dedicados a divinidades acuáticas con propiedades curativas y, en ellos, no se ocultan advocaciones específicas como Sequana (Beirâo et alii 1985: 120-124; Berrocal 1992: 194).

En suma, Garvâo nos ofrece los restos de las ofrendas entregadas en un santuario cercano, intencionadamente desocupadas para ser amortizadas en la favissa y por tanto proclives a un grado de mayor divagación en las interpretaciones sobre el ritual y la advocación venerada en el santuario de Capote, como recuerda oportunamente Virgilio H. Correia (1996: 105). Aún así los vestigios parecen implicados en ritos colectivos que suponen una ofrenda o una ingesta de comida y bebida similar a la documentada en Capote pero, a diferencia de éste, la favissa o bothros alentejana presenta restos suficientes para afirmar el culto a una divinidad salutífera y protectora, no exenta de cierto carácter ctónico. No en vano, los excavadores de Garvâo relacionaron tal culto con el tradicional del lugar a Santa Luzía, cuya ermita cercana aún sigue congregando numerosos peregrinos a finales del Otoño (Beirâo et alii, 1985: 124; Correia 1996: 104)- ${ }^{4}$.

Como ya propusimos en 1992 (BerrocalRangel 1992: 194 y en la misma línea Gomes y Silva 1994: 38), esta advocación de Garvâo tiene una fácil identificación en la divinidad prerromana Ataecina, sincretizada en Tanit y Proserpina, y posteriormente en Santa Lucía como sabemos por el santuario de El Trampal, Cáceres (Abascal, 1995). Por ello el carácter ctónico de Ataecina justificará la interpretación de las "lamparinas" que C. Beirâo y el resto del equipo descubridor de Garvâo aplicaron a las numerosas escudillas y cuencos "miniatura" del conjunto, buscando paralelos en santuarios itálopúnicos como el de Gaggera, en Selinunte (Beirâo et alii 1985: 105).

4 Una vez más recordamos al Dr. Caetano de Mello Beirâo, quien en 1989 nos permitió estudiar detalladamente los fondos de este depósito y nos acompañó al lugar del hallazgo, aportándonos numerosas informaciones de detalle y sugerencias interpretativas. Hago extensivo este agradecimiento al resto del personal del entonces I.P.P.A. de Évora, António Carlos S. Silva, Rui Parreira y Virgilio H. Correia.

5 Índice de la escasa "helenización" del comercio y de las costumbres de estos Célticos, que contrasta con la abun-
Pero tal interpretación no explica la presencia de otras "miniaturas" con forma de vasos, ni puede hacerse extensiva a las miles de escudillas grandes, con diámetros de 19 a $21 \mathrm{~cm}$. por término medio. En ninguna, de las muchas que pudimos analizar visualmente, pudimos documentar resto de combustión alguna. Por el contrario, el uso de estas escudillas como portadores de alimentos parece una interpretación más lógica, aunque en este caso no se registren datos sobre lo que portaban.

2.4. Esta conjunción, vasos modelados y ricamente decorados con motivos incisos, plásticos, impresos o excisos, y escudillas de cocciones oxidadas y fabricación a torno, parecen formar por tanto un juego básico en la vajilla de mesa de los pueblos célticos del Suroeste- ${ }^{5}$. Si la funcionalidad de ambos tipos, uno para contener bebidas de cierto prestigio (de ahí las decoraciones) y otro para alimentos semisólidos, parece fuera de dudas, su significado colectivista y su contexto eminentemente indígena (tanto en Garvâo como en Capote son escasísimas las cerámicas importadas) merecen la comparación con un pequeño conjunto de vaso y escudillas de plata halladas en Monsanto, en los límites de la región de la Beira con el Alentejo (Castelo Branco, Portugal).

El llamado "tesoro de Monsanto" fue descubierto de manera casual a mediados del siglo XX y permaneció en la colección particular "Barros e Sá" hasta su definitivo depósito en los fondos del Museu Nacional Leite do Vasconcellos (Gomes y Beirâo 1988: 125 ss.). Se compone de tres catinos o cuencos abiertos, helenísticos de tipo mastoi, y un vaso de perfil en "S", este ricamente decorado con motivos geométricos en bandas, troquelados y repujados a lo largo del hombro y cuerpo hasta la base, un tipo muy generalizado en el Mediterráneo de los siglos III y II a. C. con un ejemplar prácticamente idéntico en el Museo Nacional de Madrid (ibídem, fig.: 8.A) y varios en el conjunto mayor y más conocido de Tivissa (Raddatz 1969: 259; Almagro-Gorbea 1990: 120121) $-{ }^{6}$. Si bien no puede decirse que exista una equivalencia entre los vasos cerámicos de tipo "Capote-Garvâo" y estos modelos, entre otras

dancia de formas y juegos en la vajilla ibero-turdetana e, incluso, en la "orientalizante" de zonas cercanas (p.e. en Cabrera 1995: 146; Ruiz Mata 1995: 183 ss.).

6 En Tivissa es significativa la aparición de otras formas, copas con asas entre ellas, interpretada por AlmagroGorbea como signo inequívoco de la romanización del proceso helenizante. En Lusitania, otros depósitos, ya en bronce, confirman esta interpretación, como se observa en Moldes (Viana do Castelo: Fabiâo 1999: 172 ss.). 
cosas porque muestran técnicas y desarrollos decorativos diferentes, es fácil observar similitudes formales y deducir otras funcionales a partir de la unicidad de los tipos en conjunto.

Desgraciadamente se desconocen las circunstancias del hallazgo y los materiales que pudieran acompañarlos, aunque el estudio de Caetano Beirâo y Mario Varela Gomes dejó patente su cronología prerromana y la adscripción celtibérica de una inscripción incisa, en el exterior de uno de los cuencos, con el antropónimo Alisos Assas Balaisocum (Gomes y Beirâo 1988: 130-133). La presencia de estos vasos fue relacionada por estos autores con la de otras vajillas en plata similares halladas en la Península, desde las citadas del Castellet de Banyoles de Tivissa (Tarragona) a Pozoblanco (Córdoba) y al cercano hallazgo de los mastoi de Padrâo (Beira), en un proceso de difusión helenísitica que adjudican, sin argumentos suficientes, a la influencia cartaginesa (ibidem: 135). Sin restar importancia al carácter helenístico de los cartagineses del Golfo de Cádiz y de Cartagena, no creemos que tales testimonios se puedan aislar de una corriente generalizada que inundó el Mediterráneo y Europa Occidental desde diversos focos, en los que la Península Itálica ha sido debidamente considerada (Remesal y Muso, eds. 1991) ${ }^{7}$. Como influencia itálica se consideran los hallazgos de Tivissa y, quizá, dentro de esta coiné, la presencia de estos vasos tenga una explicación más coherente con la realidad de un pasado en el que podían ser signados tanto por celtíberos, como es el caso, como por iberos o púnicos.

Por ello su presencia en el Suroeste peninsular, más que considerarla como testimonio de los modelos que inspiraron directamente a las vasijas indígenas, debería explicarse como resultado de la similitud de algunos tipos helenísticos con los fabricados por los indígenas. Pero esta semejanza denuncia un proceso de convergencia con raíces más antiguas que la presencia cartaginesa pudiese justificar tan al Oeste y al Interior. Así se comprende de la consideración del cuarto elemento del conjunto, los llamados "quemadores", versión rústica de los foculi itálicos que aparecen bien fechados en el Suroeste desde el siglo IV a.C. integrados ya como una producción típicamente local y de amplia difusión a uno y otro lado del Guadiana (Berrocal 1992:107-109).

7 Así lo vió Rosario Lucas cuando reinterpretó el supuesto "braserillo" de La Peña Negra de Crevillente como una significativa bandeja perlada etrusca, "un fósil-guía de especial utilidad en la individualización de las relaciones entre Etruria y otras áreas culturales" (Lucas Pellicer 1991: 339).
Por tanto, si Garvâo muestra la importancia de la bebida y la comida en los rituales propios de una advocación específica, aunque de fuerte componente colectivista, el tesoro de Monsanto nos presenta la versión elitista de las mismas costumbres culinarias, sin poder aclarar su funcionalidad sacra, pero aportando un parámetro comparativo que permite comprender la importancia de unas costumbres culinarias que restringían la presentación a una vajilla compuesta de vaso y cuenco- ${ }^{8}$. Incluso si su constatación en los depósitos de Capote y Vaiamonte incidía en un contexto de carácter comunitario cuyo carácter sacro sólo puede ser intuido ante la falta de cualquier imagen o exvoto, la continuidad de un ritual colectivo con ingesta de comida y bebida aparece asegurado por hallazgos posteriores en los que la presencia de las imágenes divinas y los elementos de culto están asegurados.

2.5. Así ocurre en la favissa romana excavada sobre los derrumbes de la otrora entrada principal del Castrejón de Capote (Berrocal-Rangel y Ruiz Triviño 2003). Esta fosa contuvo dos centenares de vasos cerámicos y vítreos de distinto tipo, asociados a una treintena de platos y a otras tantas figuritas de terracota, representaciones, éstas, de dioses típicamente romanos.

Junto a ellos, 32 lucernas de volutas ricamente decoradas y grupos menores de fuentes, morteros, cuencos y jarras nos permiten intentar reconstruir el ritual, en primera instancia por el hallazgo de algunas piezas de supuesto carácter religioso como dos llamados "osculatorios", que aparecieron en pareja de bronce y hierro. Y, en segunda, por la presencia en toda la fosa de una tierra de color ocre oscuro, indicio de haber sido quemada, con un fuerte componente oleaginoso y balsámico, éste, efecto del añadido de trementina en la combustión. Media docena de ases romanos y algunas fíbulas sirvieron para fechar el hallazgo hacia el año $45 \mathrm{~d}$. C., aunque la gran mayoría de sus materiales fueron fabricados entre el 29 a.C. y el 27 d.C.

No hemos podido localizar, por el momento, el santuario al que se asocia esta favissa, por otra parte datada en un momento en el que el castro indígena llevaba siglo y medio abandonado. Pero, emplazado sobre la entrada principal, es factible considerar que pudiera haber existido un lugar

8 Las tópicas descripciones de los esponsales de Viriato inciden en que, pese a contar con numerosa vajilla de plata y oro, el Lusitano comía y bebía manjares sencillos y bebidas poco elaboradas (Dio Cass., Frag., 73; Diod. XXXIII, 7,1). 

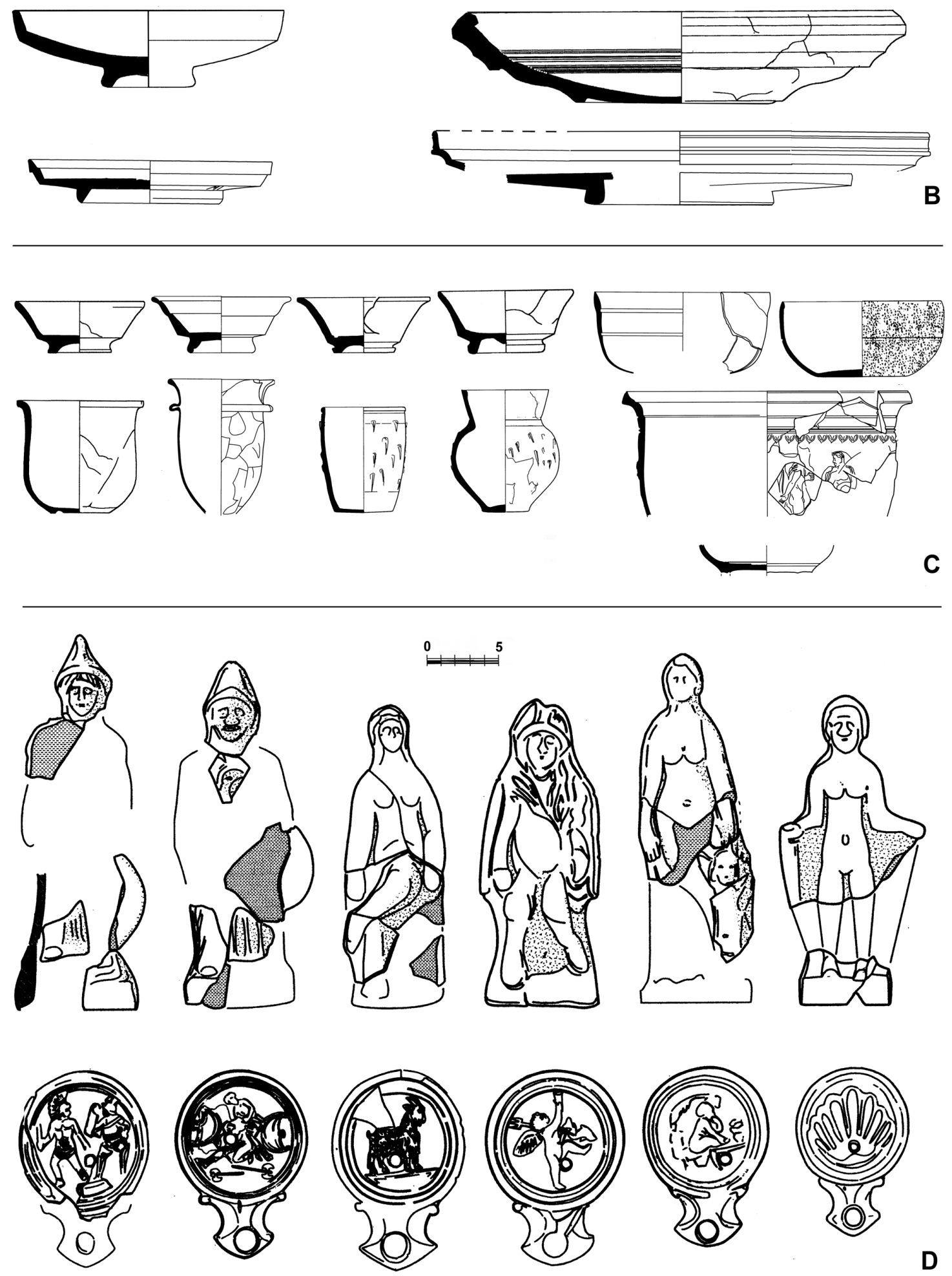

Figura 3: Selección de vasijas, lámparas y figuras de la favissa romana del Castrejón de Capote: B. Platos y Fuentes de TS; C: Copas y vasos de TS, Paredes Finas y vidrio; D. Figuras de terracotta y lucernas (a partir de Berrocal-Rangel y Ruiz 2003). 
sacro menor, heredero de otro de los tipos "ad portam" o "ante portam" definidos por AlmagroGorbea y Moneo (2000: 150-151; Moneo 2003).

La disposición ordenada que demuestra la dispersión regular de los vasos y ofrendas contenidos en la fosa, la relativa antigüedad de estos como corresponde a un uso prolongado incluso en los vidrios (con huellas de haber sido lavados numerosas veces), la utilización del fuego como agente amortizador del conjunto, el estado de fragmentación intencionada en el que se localizaron algunos materiales metálicos significativos y la presencia de estos en forma de "removedores" de aceites y perfumes, y, por último, la evidente relación con una ingesta masiva de líquidos y alimentos sólidos, nos lleva a reafirmar el carácter sagrado de la amortización de este depósito. Así deducimos que en ella se procedió a una primera "muerte ritual" con el vertido, sobre los exvotos y vasijas ordenadamente colocados, de una mezcla de aceite balsámico con abundante esencia de trementina, muy posiblemente procedente de la miera de pinos rodenos. Su ignición, gracias a la trementina, alcanzó rápidamente un poder calorímetro superior a los $800^{\circ} \mathrm{C}$ y, por las cualidades del aceite, se extendió rápidamente por todos los objetos depositados, los impregnó de una costra de tierra quemada y protegió las piezas, sin que el fuego llegara a deformarla. Esto es posible gracias a la volatilidad de la trementina pero también a que se realizó una segunda "muerte ritual" con el vertido de numerosas piedras que soterraron la fosa e hicieron añicos los vasos, lámparas y exvotos, excepto los protegidos por las bolsas de aire formadas por la acumulación de piedras.

El reparto regular de los vasos cerámicos y vítreos, junto con la relación aproximada entre las figuras de terracota (24 unidades) y las lucernas (de 25 a 32 unidades) permite colegir que este conjunto es el vestigio de un solo acto litúrgico, aunque este pueda ser la destrucción de los restos acumulados en un santuario cercano. De todas formas, el ritual incide de nuevo en la coparticipación de un grupo numeroso de asistentes que, también aquí, ingirieron bebida y comida como parte del ceremonial. Sin embargo las diferencias del acto, en relación con lo que se deduce de los ejemplos prerromanos analizados, son notables. Assí, al número de 129 vasos registrados no corresponde otro tanto de escudillas o cuencos sino, por el contrario, 27 platos y 7 fuentes. Ello permite suponer que, en el supuesto santuario de época romana de Capote, se bebía más que se comía y que la comida pudiera ser compartida a partir de la presencia de platos $\mathrm{y}$, sobre todo, de fuentes.

9 Actualmente en estudio por nosotros mismos en colaboración con un equipo formado por su descubridor y los
Esto nos induce a pensar que no sólo se trata de nuevas costumbres en el consumo sino de diferentes preparaciones culinarias, preparaciones donde los alimentos sólidos tendrían una incuestionable presencia sin que se olviden salsas y otros productos semi-líquidos, considerables a partir de la presencia de morteros "legionarios" entre las vasijas. De la misma manera es posible opinar que se produjo un cambio claro en los patrones de bebida, pues han desaparecido totalmente los vasos hechos a mano y de tamaños considerables (cir. 30-75 cl.), y se constata con exclusividad la presencia de vasitos de Paredes finas, cubiletes y copas de dos asas (cir. $25 \mathrm{cl}$.) apreciados en ambiente legionarios en relación con el vino (Haalebos y Willems, 1999: 247; Beltrán et alii 1999: $154 \mathrm{ss})$.

De la iconografía de las terracotas y lucernas, recurrente en temas lúdico-guerreros, amatorios y protectores de la Juventud, especulamos sobre la existencia de un culto sincrético con las divinidades de Minerva - Venus - Cibeles, un polimorfismo "protector" y "fecundador" que recuerda a las características de Ataecina, como también de otras divinidades no peninsulares como Fortuna. Y, en relación con la ingesta masiva de vino cabe recordar la asociación del culto a esta diosa de origen heleno, que era representada con una pátera en la mano izquierda. No aparece ninguna representación reconocible como tal en el depósito altoimperial de Capote, pero son más que numerosas las halladas en otra favissa de la Beturia Céltica, la localizada pocos años después a los pies del castillo de San Pedro.

2.6. El Castillo de San Pedro, en el cerro homónimo del término de Valencia del Ventoso (Badajoz), es la fortificación templaria más meridional documentada con seguridad. Su emplazamiento fue abandonado y cayó en el olvido tras la adscripción de las posesiones del Temple a la Orden de Santiago, hasta el hallazgo casual, a sus pies, de un importante depósito de terracotas romanas y lucernas acaecido en 1985 tras unas lluvias torrenciales que debieron erosionar el lugar de una supuesta favissa (Berrocal-Rangel 1992, 124 y fig.: 21.a; Gómez-Pantonja y Prada 2000). Sus materiales fueron cuidadosamente recogidos por un investigador local, D. Aurelio Salguero Marín, quien posteriormente lo depositó en el Museo Arqueológico Provincial de Badajoz $^{-}$, aunque dada la procedencia de los materiales, muchos quedaron en el lugar y hallazgos posteriores dieron lugar a una primera publicación concreta gracias a la actuación de la arqueóloga Alicia Prada, vecina de Valencia (vide supra). 


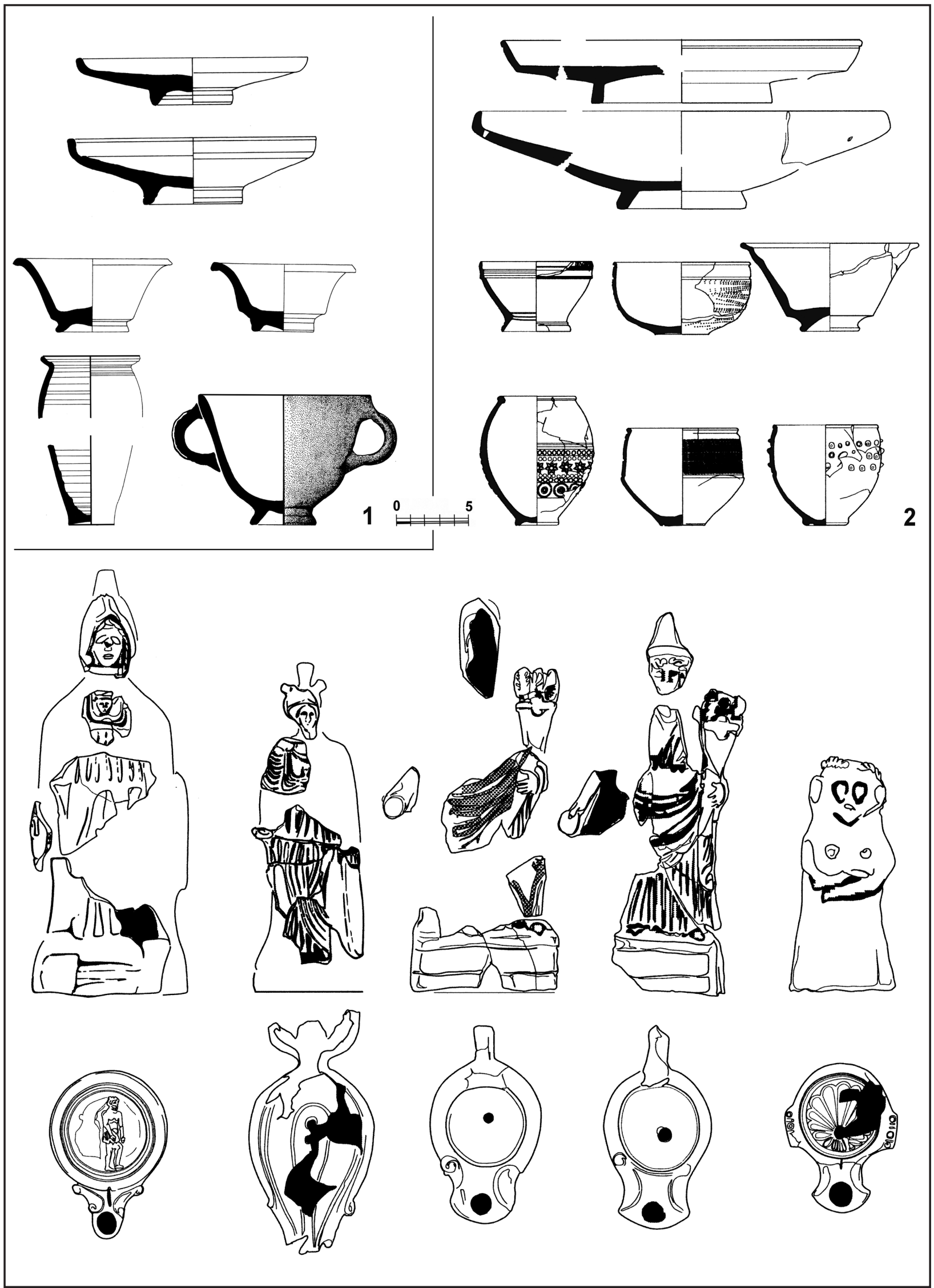

Figura 4: 1. Vasijas romanas de Vaiamonte (a partir de Fabiâo 1996); 2. Selección de vasijas, lámparas y figuras de la favissa de San Pedro: B. Platos y Fuentes de TS; C: Copas y vasos de TS, Paredes Finas y vidrio; D. Figuras de terracotta y lucernas. 
El interés de este nuevo depósito romano es la confirmación de las asociaciones avanzadas en Capote: numerosos vasos de Paredes Finas, junto a platos y fuentes más escasos, y lucernas y terracotas de divinidades. Y el conjunto, esta vez fechable en la segunda mitad del siglo I d.C., aporta identificaciones más claras dada la consolidación del proceso de romanización de la Beturia, y de la Céltica en general, pues junto a un número importante de las Minervas armadas típicas de Capote, aparece mayoritaria la figura de Fortuna, que porta en la mano derecha la citada pátera $\mathrm{y}$, en la izquierda, una característica cornucopia. El dato más interesante que podemos aportar aquí es la re-identificación de esta Fortuna, que seguimos creyendo Ataecina entre los indígenas, con la imagen representada en la conocida pátera de Bandua Araugelensis de la colección Calzadilla de Badajoz (Blanco 1959, 458; Blázquez 1962: 55 ss. y 1983: 281-283; Olivares 2002: 153). Todo este ambiente sagrado, sin precedentes ni elementos indígenas conocidos, permite explicar la introducción del consumo popular de vino como una novedad asociada a la "romanización" del culto. Por ello muy cerca de Capote, en las ruinas del municipium de Nertobriga Concordia Iulia, fue exhumado en 1890, un espectacular vaso de bronce, "kernos" ritual decorado con detalladas escenas de vendimia y temas báquicos (García y Bellido 1957).

\section{Conclusiones}

De los cinco casos analizados se pueden extraer conclusiones que, dada la escasa base documental, no pueden ser menos que provisionales. Aún así, hay datos que ofrecen pocas dudas, dada la contundencia con la que se repiten.

Es evidente que los depósitos sacros prerromanos de la Céltica del Suroeste remiten siempre a ceremonias colectivas en las que se ingiere una cierta cantidad de comida y bebida. Desconocemos el tipo de alimentos tomados, fuera de una importante proporción de carne procedente de los sacrificios realizados en el Santuario central de Capote, pero parece claro que, en cuanto a las comidas, éstas debían ser de una consistencia semisólida, propia para ser servida en escudillas, los recipientes más numerosos de los depósitos de Capote, Vaiamonte y Garvâo. En cuanto a la bebida, la falta absoluta de datos no

10 Esto no significa que el vino fuese desconocido, sino que era materia reservada a las elites, herencia de la tradición orientalizada del Hierro I y de los circuitos coloniales de consumo, como se comprueba en tierras de la Beturia Túrdula con representaciones como el Sileno Simposiasta de Capilla o el kylix de Medellín (Olmo 1992: 65-67). Pero entre los célticos del Suroeste, si hubo tal orientalización, no quedaban vestigios y, quizá por impide alguna reflexión. No siendo la zona especialmente adecuada para el cultivo vitivinícola, creemos que debía tratarse de alguna "cerveza" local o líquido similar producido por la fermentación de granos de cereal, como cita Orosio que acontecía entre los numantinos (vide supra). Por el tamaño medio de los vasos cerámicos, capaces de albergar de 33 a 75 cl., es de suponer que se trataba de una bebida de producción fácil y poco onerosa, a menos que se tomase "mezclada", al modo del vino griego -algo sin base argumental en la Península-.

En suma, nuestra interpretación de estos depósitos prerromanos apoya un valor "laico" de los rituales a los que obedecieron, cercano al symposion griego, destinado a reafirmar la solidaridad y la cohesión entre los miembros paritarios de la comunidad, basada en el carácter gentilicio de ésta (Almagro-Gorbea y Berrocal 1997: 311; Murray 1990: 3-13; Schmitt-Pantel 1985: 135$158 . . .$.$) .$

Quizá por ello estas ceremonias tuvieron un carácter anicónico en los tres casos, aunque en Garvâo figuraciones singulares en los exvotos han llevado a reconocer cierta relación con la diosa Tanit, sincretizada en la gran deidad céltica Ataecina. Y esta identificación, que no se documenta en los depósitos de Capote y Vaiamonte, parece adecuada a los testimonios posteriores de época romana.

Entonces, a lo largo del siglo I d. C., se conocen en la Beturia Céltica al menos dos "favissas" más que, ahora con exclusivo material romano, parecen recoger la tradición de los banquetes ceremoniales prerromanos, aunque con un significativo cambio en el servicio y en la forma de los alimentos ingeridos. Predominan entonces los vasos de pequeño tamaño, capaces de albergar no más de $25 \mathrm{cl}$., y por tanto destinados al consumo de dosis menores de líquidos. Es factible pensar que se trata de vino, no sólo por la importancia de esta bebida, sino por la tradición que asocia su consumo a los tipos de vasos y cubiletes que se documentan. A juzgar por los depósitos romanos de Capote y San Pedro, la bebida debió adquirir un papel principal frente a la comida que, en estos casos, se sirve en forma de alimentos sólidos acompañados de salsas y pastas- ${ }^{10}$. Además, mientras los líquidos se debían tomar en los citados recipientes individuales, la comida parece

ello, se constata la importancia de la bebida, en cantidad paritaria o prioritaria sobre la comida, lo contrario de lo interpretado en los relieves de Pozo Moro y en semejanza con lo referido por los escritores greco-latinos sobre las costumbres de los Celtíberos (Domínguez Monedero 1995: 44 y 54). 
ser compartida por grupos, a juzgar por la presencia de grandes platos y fuentes, con una distribución numérica totalmente distinta a las escudillas y vasos prerromanos del Santuario central de Capote.

Este cambio de hábitos en la preparación y en la presentación de los alimentos tiene su mejor respuesta en las diferencias inherentes al ritual que, de ser anicónico y anepígrafo -sin imágenes divinas ni dedicatorias o teónimos- pasa a ser claramente sacralizado mediante la presencia de numerosas figuritas de dioses romanos realizadas en terracota e, incluso, mediante la presencia de sellos y epígrafes en sus pedestales (GómezPantonja y Prada 2002: 400). Esta pluralidad de imágenes sagradas no obscurece la sospecha de que sean la repuesta polimorfa de una divinidad femenina, de carácter protector y ctónico -de ahí la asociación de figuras de terracota con lucernas-, una divinidad que viene a corresponder a los atributos romanos de Bona Dea - Fortuna y a los prerromanos de Ataecina que, en el caso de San Pedro, puede ser identificada con Bandua Araugelensis de la colección Calzadilla de Badajoz. La pátera en su mano, en actitud de proceder a una libación, y el hallazgo en la cercana ciudad de Nertobriga del citado "kernos", calathos de bronce con una conocida escena de vendimia vienen ratificar la importancia novedosa que el vino adquirió en estos momentos en la Céltica del Suroeste, importancia investida de un carácter sacro indudable y que tiene su correspondencia en tierras vitivinícolas cercanas, insertas ya en el territorio emeritense (Calero 1995 y 2002).

Madrid, Julio de 2004

\section{BIBLIOGRAFíA}

ABASCAL PALAZÓN, J.M., 1995: "Las inscripciones latinas de Santa Lucía del Trampal y el culto a Ataecina en Hispania.", AespA, 68, 31-106.

ALIMENTARIA 1991: Alimentaria. Estudios en homenaje al Dr. Michel Ponsich, Anejos de la revista Gerión, III, Madrid.

ALMAGRO-GORBEA, M., 1990: "L'Hellenisme dans la Culture iberiqe.", XIII Internationalen Kongresses für Klassische Archäologie (Berlin 1988): 113-127, Mainz am Rhein.

ALMAGRO-GORBEA, M., 1996: Ideología y poder en Tartessos y el Mundo Ibérico., R. Académica Historia, Madrid.

ALMAGRO-GORBEA，M.; BERROCAL-RANGEL，L., 1997: "Entre iberos y celtas: Sobre santuarios comu- nales urbanos y rituaes gentilicios en Hispania.", Quaderns de Prehistòria i Arqueología de Castelló, 18: 567-588.

ALMAGRO-GORBEA, M.; MONEO, T., 2000: Santuarios urbanos en el Mundo ibérico., BAH, 4, Madrid

ANTUNES, M.T.; CUNHA, A.S., 1986: “O crânio de Garvâo (século III a.C.): causa mortis, tentativa de interpretaçâo.", Trabalhos de Arqueología do Sul, 1: 7986, Évora.

ARNAUD, J. M.; GAMITO, T.J. 1974-1977: "Cerâmicas estampilhadas da Idade do Ferro do Sul de Portugal. I - Cabeça de Vaiamonte - Monforte.", OArqP, ser. III, 7-9: 165-202.

BARRIO MARTÍN, J., 1989: "Los vasos trípodes de la necrópolis de Las Erijuelas de S. Andrés (Cuéllar).", OArqP, 5: 101-123.

BARRIO MARTÍN, J., 1999: La II Edad del Hierro en Segovia (España)., BAR IS 790, Oxford.

BEIRÂO, C. DE M.; TAVARES, C.; SOARES, J.; GOMES, M. V. y GOMES, R., 1987: "Um depósito votivo da II Idade do Ferro, no Sul de Portugal, e a suas relaçôes com as culturas da Meseta.", Studia Paleohispanica (IV CLyCP) - Veleia, 2-3: 207-221.

BEIRÂO, C. DE M.; TAVARES, C.; SOARES, J.; GOMES, M.; GOMES, M. V. y GOMES, R., 1985: "Depósito votivo da II Idade do Ferro de Garvâo. Noticia da primera campanha de escavaçôes.", OArqP, ser. IV, $\mathrm{n}^{\mathrm{o}}$ 3: $45-135$

BELTRÁN LLORIS, M.; ORTIZ, M. E.; PAZ PERALTA, J.A. 1999: "La vajilla relacionada con el vino en Hispania." En S. Celestino, ed., El vino en la Antigüedad romana: 129-200, Madrid.

BERROCAL-RANGEL, L., 1992: Los pueblos célticos del Suroeste de la Península Ibérica. Complutum Extra 2, Madrid.

BERROCAL-RANGEL, L., 1994: El Altar prerromano de Capote. Ensayo etnoarqueológico sobre un ritual céltico en el Suroeste Peninsular. UAM, Madrid.

BERROCAL-RANGEL, L.; RUIZ TRIVIÑO, C., 2003, $E l$ Depósito Alto-imperial de Capote. Memorias de Arqueología Extremeña, 5, Mérida.

BLÁZQUEZ MARTÍNEZ, J.M. 1962: Religiones Primitivas de Hispania, I. Fuentes literarias y epigráficas, C.S.C.I., Madrid.

BLÁZQUEZ MARTÍNEZ, J.M., 1983: "La religión indígena”, en R. Menéndez Pidal, ed., Historia de España, II.2: 261-321; Espasa-Calpe, Madrid.

CABRERA BONET, P., 1995: "La comercialización del vino griego en la Hispania prerromana.", en S. Celestino, ed., Arqueología del Vino; 137-156, Jerez de la Frontera. 
CALERO CARRETERO, J.A., 1995: "A propósito de una pieza de la Colección Monsalud de Almedralejo.", XVI Jornadas de Viticultura y Enología de Tierra de Barros (Almedralejo, 1994), 707-718.

CALERO CARRETERO, J.A., 2001: "Aportaciones a la romanización de Tierra de Barros.” Actas II Jornadas de Humanidades Clásicas (Almedralejo, 2000), 23-29.

CELESTINO PÉREZ, S., ed., 1995: Arqueología del Vino. Los orígenes del vino en Occidente., Jerez de la Frontera.

CELESTINO PÉREZ, S., ed., 1999: El vino en la Antigüedad, Serie Varia UAM, 4, Madrid.

COHEN, M.N. 1984: La crisis alimentaria de la Prehistoria., Alianza U., Madrid.

CORREIA, V.H., 1996: "O sítio arqueológico de Garvâo e o seu depósito ritual.”, J. de Alarcâo - A. I. Palma Santos, eds., De Ulisse a Viriato. O primeiro milénio a. C.: 101-106, Lisboa.

CORREIA, V.H., 1999: "Algumas consideraçôes sobre os centros do poder na Proto-história do Sul de Portugal.", Revista de Guimarâes (Congresso de Protohistória Europeia, vol. 1): 699-714.

DOMÍNGUEZ MONEDERO, A., 1995: "Del simposio griego a los bárbaros bebedores: El vino en Iberia y su imagen en los autores antiguos.", en S. Celestino, ed., Arqueología del Vino; 21-72, Jerez de la Frontera.

DUMEZIL, G. 1977: La religione romana arcaica., Milano.

FABIÂO, C., 1996: "O povoado fortificado da Cabeça de Vaiamonte (Monforte).”, A Cidade. Revista Cultural de Portoalegre, 11: 35-84.

FABIÂO, C., 1999: "A propósito de Moldes, Castelo de Neiva, Viana do Castelo: a baixela romana tardorepublicana em bronze no extremo ocidente peninsular.", Revista Portuguesa de Arqueología, 2.1: 163-198.

FERNANDES, T. M., 1986: "O crânio de Garvâo (século III a.C.): analise antropologica.”, Trabalhos de Arqueología do Sul, 1: 75-78, Évora.

FEUGÈRE, M.; ROLLEY, C. eds., 1991: La vaiselle tardorepublicaine en bronze. Centre Recherches TEchniques Gréco-romaines, 13, Université de Bourgogne, Dijon.

GARCÍA Y BELLIDO, A. 1957: "Viaje arqueológico por Extremadura y Andalucía.”, AespA, 30: 233-236.

GOMES, M. V.; BEIRÂO, C. DE M., 1988: "”O tesouro da Colecçâo Barros e Sá, Monsanto da Beira (Castelo Branco).", Veleia, 5: 125-136.

GOMES, M. V.; SILVA, C. T., 1994: "Garvâo: une sanctuaire protohistorique du Sud du Portugal.", Les Dossiers d Archeologíe, 198: 34-39.

GÓMEZ-PANTOJA, J.; PRADA GALLARDO, A., 2000: "Las terracotas del cerro de San Pedro (Valencia del Ventoso, Badajoz).”, Hant, XXIV, 383-409.
HAALEBOS, J.K.; WILLEMS, W.J.H. 1999: "Recent research on the limes in the Netherlands.", Journal of Roman Archaeology, 12: 247-262.

LORRIO ALVARADO, A.J. 1988-1989: “Cerámica gris orientalizante de la necrópolis de Medellín (Badajoz).”, Zephyrus, LXI-LXII: 283-314.

LUCAS PELLICER, M.R., 1991: "Bandeja etrusca de borde perlado hallada en el poblado de La Peña Negra (Crevillente, Alicante).”, en J. Remesal y O. Musso, eds., La presencia del material etrusco..... 338367, Barcelona.

MARKALE, J., 1989: Druidas. Tradiciones y dioses de los celtas., Tauros Humanidades, Madrid.

MONEO, T. 2003: Religio ibérica., BAH, 20, Madrid.

MONTANARI, M. 1993: El hambre y la abundancia. Historia y cultura de la alimentación en Europa., Crítica, Barcelona.

MORALES MUÑIZ, A.; LIESAU, C., "Estudio de la fauna recogida en torno al altar." en Berrocal-Rangel, L. El Altar prerromano de Capote: 289-298.

MURRAY, O. 1990: "Sympotic History.”, en Sympotica. A Symposium on the Symposion: 3-13, Oxford.

OLIVARES, J. C., 2002: Los dioses de la Hispania Céltica. BAH, 15, Madrid.

OLMOS, R., ed., 1992: La sociedad ib́ rica a través de la imagen., Barcelona - Madrid.

QUESADA SANZ, F., 1994: "Vinos, aristócratas, tumbas y guerreros en la Cultura ibérica (Ss. V - II a. C.).”, Verdolay, 6: 9-124, Murcia.

RADDDAT, K., 1969: Die Schatzfunde der Iberischen Halbinsel vom Ende des Dritten bis zur Mitte des Ersten Jahrhunderts Ge. Untersuchumgen zur Hispanischen Toreutik, MF, 5, Berlin.

REMESAL, J.; MUSSO, O., eds., 1991: La presencia de material etrusco en la Península Ibérica., Universitat de Barcelona.

RUIZ MATA, D., 1995: "El vino en época prerromana en Andalucía Occidental.", en S. Celestino, ed., Arqueología del Vino; 157-212, Jerez de la Frontera.

SCHMITT-PANTEL, P. 1985: "Banquet et cité grecque. Quelques questions suscitées par les recherches récentes.", $M E F R, 97:$ 135-158.

VV.AA.1987: L'Alimentazione nel Mondo antico. Gli Etruschi, Roma. 